\title{
Numerical Simulation Analysis of Subway Station Deep Excavation Pit
}

\author{
Do Minh Ngoc ${ }^{1, \mathrm{a}}$, Wu li ${ }^{1, \mathrm{~b}}$, Do Minh Tinh ${ }^{2, \mathrm{c}}$, Zhang Li-jun ${ }^{1, \mathrm{~d}}$ \\ ${ }^{1}$ China University of Geosciences (Wu Han) \\ ${ }^{2} \mathrm{Ha}$ Noi Architectural University (Viet Nam)

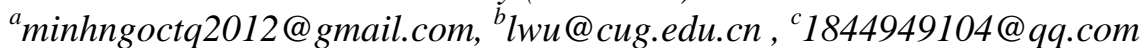 \\ ,dcugzlj@163.com
}

\begin{abstract}
:
Excavation and shoring of deep foundation pit for subway station is a kind of very complex engineering. Existing shoring calculation theory is limit equilibrium method based on the rigid plastic theory, the shoring's structural force is the limiting force when the failure happens, so the actual stress on the shoring structure in use can't be calculated, the foundation pit deformation is just a estimate based on experience, shoring design mostly relies on the practical experience, and as a result it is very difficult to design a safe, reasonable and economic shoring structure. In comparison with the theory method, the numerical simulation is advantageous in terms of calculation of actual stress and displacement. Before excavation of deep foundation pit, numerical simulation can be used to analyze the mechanism and cause of foundation pit deformation and failure, therefore reasonable effect can be achieved by adjusting the shoring. Taking Antuoshan Station of Shenzhen Subway Line 7 as an example, this thesis uses FLAC $^{3 \mathrm{D}}$ numerical simulation analysis and proves that this software's application in foundation pit engineering can sufficiently supplement the calculation theory.
\end{abstract}

Keywords: Deep excavation pit, FLAC3D, numerical simulation, subway station

\section{Introduction}

In the course of construction of deep foundation pit for high-rise building and other engineering, the shoring structure and soil interact with each other and steadily adjust respective stress and deformation to make the soil body inside and outside of the foundation pit stable or unstable. This is a physical process with complex mechanism. Making of relevant numerical simulation and analysis for it is undoubtedly meaningful for improving the design theory and construction level of the deep foundation pit. Popular traditional calculation methods include equivalent beam method, Terzaghi method, Yama Kunio Method, elastic beam method, elastoplasticity method, etc ${ }^{[18]}$. Along with the development of computer technology, finite element method is introduced in shoring calculation. At present, frequently used finite element method is one-dimensional finite element method formed based on elastic foundation beam method, and two-dimensional finite 
element method based on Biot's consolidation theory. Foresaid methods simplify the three-dimensional problems of foundation pit shoring system to one-dimensional or plane problems and fail to reflect the actual conditions of support shaft force and foundation pit displacement. This thesis uses FLAC $^{3 \mathrm{D}}$ (Fast Lagrangian Analysis of Continua in 3-Dimensions) to numerically simulate the excavation and shoring of Antuoshan Station of Shenzhen Subway Line 7 and accordingly analyze deformation of soil body inside and outside of the foundation pit and the horizontal displacement of soil body behind the wall. FLAC ${ }^{3 \mathrm{D}}$ utilizes a governing differential equation displaying finite difference formulation and solution field and mixed element discrete model, can accurately simulate material yield, plastic flow, softening and even large deformation, and especially has unique advantage in terms of material elastoplasticity analysis, large deformation analysis and construction process simulation, etc.

\section{Formation of FLAC ${ }^{3 \mathrm{D}}$ Model}

FLAC $^{3 \mathrm{D}}$ software ${ }^{[1]}$ was firstly developed by ITASCA Consulting Group Inc. in 1986. It is an international geomechanics engineering consultant and has grown to be a famous innovative solution to actual problems related to geomechanics. It is mostly used in mining, civil works, petroleum, national defense, waste recovery, etc. it was firstly introduced to China in early 1990s, mainly for mechanical analysis of rock and soil. FLAC ${ }^{3 \mathrm{D}}$ offers 11 built-in material models for various materials, such as elastic isotropy, Drucker-Prager elastoplasticity, Mohr-Coulomb elastoplasticity, etc., with five computation methods, namely, static force, dynamic force, creepage, transfusion and temperature, can conduct multi-mode coupling analysis, and has multiple structural units, such as beam unit, cable unit, pile unit, liner unit, etc. These structural units can fast, conveniently and accurately simulate the process of consolidation by different structures on rock-soil body. The specific material models in FLAC $^{3 \mathrm{D}}$ are as follows ${ }^{[2]}$ :

(1) One excavation model "null";

(2) Three elasticity models (isotropic, transverse isotropic and orthogonal isotropic elasticity models);

(3) Six plasticity models (Drucker-Prager model, Molar-Coulomb model, strain-hardening and softening model, ubiquitous-joint model, dual-linear strain-hardening and softening ubiquitous-joint model, and modified Cambridge model).

The failure envelope of Mohr-Coulomb model is determined according to Mohr-Coulomb criterion. Incremental theory of plasticity assumes that strain increment of rock-soil body can break up into elastic strain increment $e_{i}^{E}$ and plastic strain increment $e_{i}^{P}$ :

$$
\Delta e_{i}=e_{i}^{E}+e_{i}^{P}(i=1,2,3)
$$




\subsection{Choice of finite element types}

Tetrahedron unit and hexahedral unit are common three-dimensional finite elements ${ }^{[3]}$. The latter consists of the former. However, for the purpose of boundary with regular form, hexahedral unit is better than tetrahedron unit or combined hexahedron. Frequency of displacement deformation function determines hexahedron to be a unit of high frequency. The quantity of unit can be reduced in simulation of deep foundation pit excavation, but excavation depth, dewatering scheme and soil layer must be considered in grid division, thus the grid density is increased ${ }^{[6,7]}$. Therefore, simulation of excavation process should use hexahedral unit. The shoring system generally bears shaft force, so bar unit is used.

\subsection{Constitutive model of soil body}

Soil is a kind of very complex compound with complex mechanical behaviors. Under the action of external forces, soil body will be deformed elastically, and also be deformed plastically and irretrievably. The report uses Mohr-Coulomb elastic-plastic model for computation. Mohr-Coulomb yield criterion is as follows ${ }^{[9]}$ :

$$
f_{s}=\sigma_{1}-\sigma_{3} N_{\phi}+2 C \sqrt{N_{\phi}}
$$

Where, $N_{\phi}=\frac{1+\sin \phi}{1-\sin \phi}$, $\mathrm{C}$ is cohesive force and $\phi$ is frictional angle.

Tensile stress yield function is defined as follows:

$$
f_{t}=\sigma_{t}-\sigma_{1}
$$

Where, $\sigma_{t}$ is tensile strength.

After yield, the soil body will be partly elastic and partly plastic. In any course of stress increment, its strain consists of component of elasticity and component of plasticity, therefore:

$$
d \varepsilon_{i j}=\left(d \varepsilon_{i j}\right)_{e}+\left(d \varepsilon_{i j}\right)_{p}
$$

Elastic strain component can be computed easily. To derive the relation between plastic strain component and stress increment, material characteristics must be further assumed. It is assumed that the relation between plastic strain component and plastic function $\mathrm{Q}$ is as follows ${ }^{[3]}$ :

$$
\left(d \varepsilon_{i j}\right)_{p}=d \lambda \frac{\partial Q}{\partial \sigma_{i j}}
$$

FLAC $^{3 \mathrm{D}}$ defines respectively shear plastic flow and tensile stress plastic flow, which correspond to different flow rule. The shear potential function $g$ corresponds to a non-associated flow rule, with the following formula ${ }^{[1]}$ : 


$$
g_{s}=\sigma_{1}-\sigma_{2} N_{w}
$$

Where: $N_{\psi}=\frac{1+\sin \psi}{1-\sin \psi} ; \psi$ is dilatancy angle。

Potential function g corresponds to associated flow rule for tensile failure, with the following formula:

$$
g_{t}=-\sigma_{3}
$$

In $\mathrm{FLAC}^{3 \mathrm{D}}$, bulk modulus $\mathrm{K}$ and shear modulus $\mathrm{G}$ contain more basic material characteristics than elastic modulus $\mathrm{E}$ and Poisson's ratio, therefore the elasticity parameters should be converted into K and G, with the following conversion formula ${ }^{[1]:}$

$$
\begin{aligned}
& K=\frac{E}{3(1-2 v)} \\
& G=\frac{E}{2(1+v)}
\end{aligned}
$$

\subsection{Mathematic model of contact surface deformation}

Due to the big difference of elastic modulus between soil and envelop enclosure material, the interface of the both usually has big shearing strength ${ }^{[13]}$. To reasonably simulate this case, contact surface unit is set up at the interface. Contact surface unit includes two material models: stratified material unit and contact friction unit. Goodman contact friction unit is mostly applied. This unit has no thickness and simulates the slip and tension crack of contact surface, but under pressure, a big normal stiffness coefficient is used for computation. This inevitably brings in some error to the computation result. Actually, mutual shearing and movement between two kinds of materials are not necessarily just along the interface of the materials, but may also happen inside the soil, and thus the unit without thickness may not certainly reflect the real deformation characteristics of contact surface. The thin-layer quadrilateral unit proposed by Desai and others has no this defect of contact friction unit and can reflect quite well normal deformation and tangential deformation and stress transfer.

\subsection{Anchoring simulation}

Fast Lagrangian Analysis of Continua ${ }^{[4]}$ in 3-Dimensions uses anchor unit to simulate anchoring effect. The anchor unit is a double-node linear unit and each node has only one degree of freedom along the axial direction of the unit. One actual anchor cable can be divided into several anchor units. The anchor unit can produce tensile deformation along its axial direction and yield. Anchor unit nodes can have relative displacement with entity unit and contact parameters $\mathrm{f}, \mathrm{c}$ and $\mathrm{k}$, which respectively represent friction coefficient, cohesion and rigidity, can be set up between them to simulate the grouting effect. Shearing yield, slip and even pulling failure can occur between anchor unit and rock body. Anchor unit nodes can connect with entity unit without occurrence of relative displacement. Pre-tensile stress can be set up for anchor unit to simulate pre-stress anchor cable. 
The interaction between anchor cable (free anchor, bond anchor, pre-stress anchor, etc.) and rock body can be simulated by setting different contact modes and parameters to reach the goal of simulating anchoring effect ${ }^{[19]}$.

According to above principle, Itasca Consulting Group lnc develops Fast Lagrangian Analysis of Continua in 3-Dimensions ${ }^{[4]}$. This program can quite well simulate mechanical behaviors of geologic materials, such as failure or plastic flow, when its strength or yield reaches to the limit, and is especially applicable to analyze progressive failure and instability and big deformation simulation. It contains 10 constitutive models of elastic-plastic materials and five computation modes (static force, dynamic force, creepage, transfusion and temperature), which can couple mutually. It can simulate multiple structures, such as rock body, soil body and other material entity, beam, anchor unit, pile, shell, and manual structures, such as shoring, lining, anchor cable, rock bolt, geotextile, pile plank, interface unit, etc., and simulate complex rock-soil engineering or mechanical problems.

\section{Engineering overview}

\subsection{Engineering scale}

Antuoshan Station of Shenzhen Subway Line 7 is located at Futian District, Shenzhen. It's a transfer station between Line 2 and Line 7. Antuoshan Station of Line 2 is an underground three-floor island station while Antuoshan Station of Line 7 is an underground two-floor side station. Transfer point has been completed in conjunction with Line 2. The station site lies in the intersection between Jingwu Road (under plan) and $4^{\text {th }}$ Qiaoxiang Road and extends towards south-north Jingwu Road. The station central mileage is DK9+845.28, starting point mileage is DK9+766.355, ending point mileage is DK9+948.455, the total length of the station is $182.1 \mathrm{~m}$, the foundation pit is about 16.69-28.56 m deep and about $30.05-40.25 \mathrm{~m}$ wide, the (side) platform is $8.2 \mathrm{~m}$ wide, and the distance between centers of tracks is $5.00 \mathrm{~m}$. The station is an add-on type. The standard section is an underground two-floor two-span structure, and the north end is added on Ventilation Pavilion 1, an underground one-floor structure; the south end is added on Ventilation Pavilion 2, an underground one-floor structure. Ventilation Pavilion 2 is constructed together with the primary structure of the station. The big mileage end of the station is connected with Annong Underground Excavated Interval Tunnel while the small mileage end of the station is connected with Shen'an Mined Interval Tunnel. 


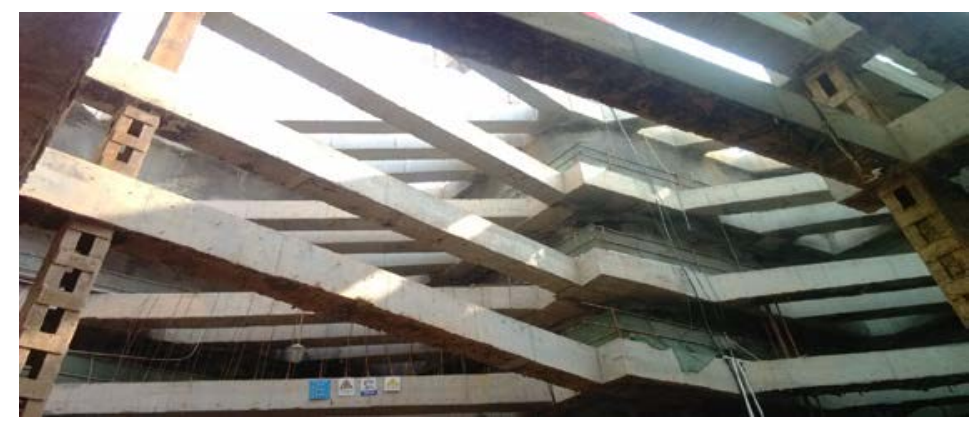

Figure 1. Construction Site of Antuoshan Station Deep Foundation Pit

\subsection{Engineering characteristics}

This engineering has the following main characteristics:

(1) Standard section engineering spans from Futian to Nanshan, so the construction coordination is difficult.

(2) There are many mined tunnels within the standard section, with complex and variable geological conditions.

(3)There are many parallel lines. In some areas, there are $200 \mathrm{~m}^{2}$ large cross sections, with big construction safety risk.

(4) There are many open-cut and aven foundation pits, and their envelop enclosures are complex, with big safety risk.

(5) Pits of some avens have many working faces, with big construction difficulty.

\subsection{Geological conditions of the engineering}

This field is covered by $\mathrm{Q}^{4 \mathrm{ml}}, \mathrm{Q}^{4 \mathrm{al}+\mathrm{pl}}, \mathrm{Q}^{\mathrm{el}}$ and covers Yanshanian granites ( $\gamma 53)$. The main stratums are described as follows:

(1) 2 Plain fill: grayish yellow, loose, slightly wet-very wet, main ingredient is sand, with a few cohesive soil and detritus, pavement hole top with $10-30 \mathrm{~cm}$ asphalt concrete, local drill with many detritus whose particle size is $2-15 \mathrm{~cm}$; evenly distributed in the filed; the layer thickness $0.50-10.20 \mathrm{~m}$, layer base elevation 30.66-46.19m; actual standard penetration test blow count 5-18 blows, and the average 10.1 blows.

(4) 9 Medium sand: isabelline, slightly dense-intermediate dense, saturated, poorly graded, with a few cosmid; distributed in lenticle near ZDK9+833.00, thickness $0.00-.30 \mathrm{~m}$, layer top burial depth $5.20-8.00 \mathrm{~m}$, layer top elevation 41.56-46.40m; actual standard penetration test blow count 15-30 blows, and the average 22.5 blows.

(4) 11 Gravelly sand: isabelline, slightly dense, saturated, main ingredient is quartz granule, well graded, with a few cosmid; distributed in lenticle near DK9+825.00; thickness 0.00-4.30m, layer top burial depth 3.70-8.00m, layer top elevation 40.97-46.19m; actual standard penetration test blow count 11 blows. 
(7)1 Gravelly cohesive soil: isabelline, stiff-plastic stiff, with much quartz granule formed by residual saprolitic soil from granite, rough, easy to disintegrate with water, distributed in sections DK9+836.052 DK9+990.00 and ZDK9+850.00 ZDK9+990.00; layer thickness: 0.00 7.60m, layer top burial depth: 1.50 8.00m, layer top elevation 34.03 41.90; actual standard penetration test blow count 13 -35 blows, and the average 23.4 blows, correction blow count: 12.0 28.9 blows, and the average 20.4 blows.

(8) 1 Completely weathered granite: the rock body presents as rigid soil, easy to loosen by pinching and easy to disintegrate with water; except in the south end of the station, they are distributed in other areas in the field; thickness: $0.00 \sim 8.90 \mathrm{~m}$, average thickness: 3.76, layer top burial depth: $0.80 \sim 14.10 \mathrm{~m}$, layer top elevation: 30.26 44.10m; actual standard penetration test blow count 35 60 blows, the average 46.0 blows; correction blow count: 30.2 45.5 blows, and the average 37.2 blows.

(8)2 Strong weathered granite: original rock structure is still identifiable, the rock body presents as soil with detritus and fragment; disintegrated when immersed in water; weathering fracture is very developed; distributed everywhere in the field; the maximum exposure thickness $16.30 \mathrm{~m}$, layer top burial depth: 0.50 23.00m, layer top elevation: $25.06 \sim 41.17 \mathrm{~m}$; actual standard penetration test blow count 58 150 blows, the average 89.9 blows; correction blow count: $50.1 \sim 117.9$ blows, and the average 70.6 blows.

(8)3 Intermediately weathered granite: intermediate to coarse grain structure, massive structure; rock body presents as fragment and bulk, fracture is developed; distributed everywhere in the field; the maximum exposure thickness $12.40 \mathrm{~m}$, layer top burial depth: 2.60 30.00m, layer top elevation: 12.80 38.27m;

(8) 4 Slightly weathered granite: intermediate to coarse grain structure, massive structure; rock body presents bulk; with a few weathering fracture; hard rock; distributed everywhere in the field; the maximum exposure thickness $24.50 \mathrm{~m}$, layer top burial depth: 2.00 32.50m, layer top elevation: 10.95 39.18m; according to laboratory test result, the range value of saturated uniaxial compressive strength of slightly weathered granite in this field is 55.40 92.30Mpa, the standard value is $60.7 \mathrm{MPa}$; it is hard rock, complete, and the basic quality grade of rock body is grade II.

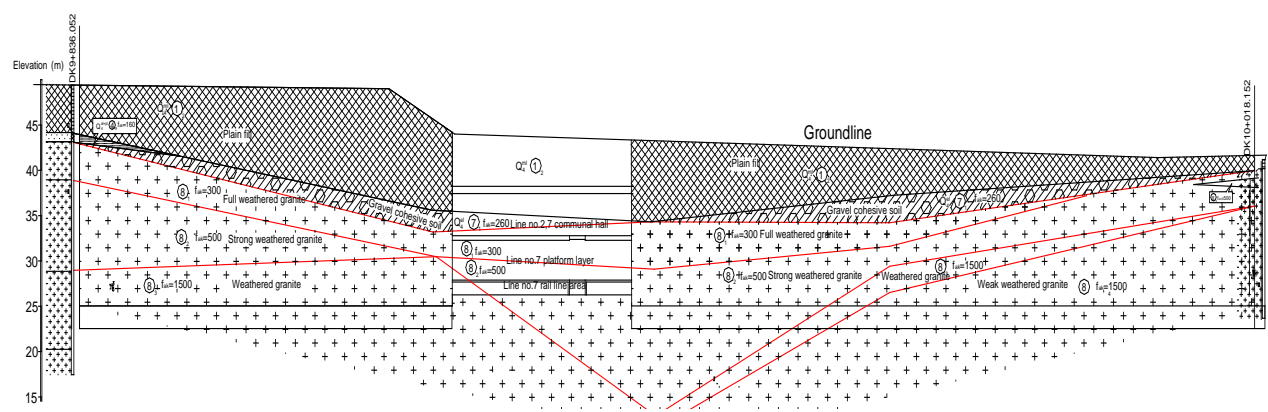


Figure 2. Longitudinal Profile of Geology of Antuoshan Station

Table 1. Stratum Computation Parameters

\begin{tabular}{|c|c|c|c|c|c|}
\hline $\begin{array}{l}\text { Rock- soil } \\
\text { layer }\end{array}$ & Rock-soil name & $\begin{array}{c}\text { Average } \\
\text { thickness [m] }\end{array}$ & $\begin{array}{c}\text { Volume-weight } \\
{\left[\mathrm{KN} . \mathrm{m}^{2}\right]}\end{array}$ & $\begin{array}{c}\text { Elasticity } \\
\text { Modulus [Mpa] }\end{array}$ & $\begin{array}{l}\text { Poisson's } \\
\text { ratio }\end{array}$ \\
\hline (1)2 & Plain fill & 4.0 & 17.5 & 5 & 0.35 \\
\hline (7) 1 & $\begin{array}{c}\text { Gravelly } \\
\text { cohesive soil }\end{array}$ & 3.5 & 19.5 & 12 & 0.3 \\
\hline (8) 2 & $\begin{array}{c}\text { Strong } \\
\text { weathered } \\
\text { granite }\end{array}$ & 4.5 & 22.5 & 46 & 0.27 \\
\hline (8) 3 & $\begin{array}{l}\text { Intermediately } \\
\text { weathered } \\
\text { granite }\end{array}$ & 18 & 24.5 & 5000 & 0.25 \\
\hline (8) 4 & $\begin{array}{c}\text { Slightly } \\
\text { weathered } \\
\text { granite }\end{array}$ & 30 & 25.0 & 22000 & 0.22 \\
\hline
\end{tabular}

\subsection{Excavation and shoring scheme}

(1) Foundation pit excavation

Foundation pit of Antuoshan Station is constructed by the "open-cut and bottom-up" method. Before construction water level of foundation pit is controlled by utilizing pump drainage of dewatering well to ensure satisfaction of excavation requirements. Foundation pit is excavated layer by layer. Layering height considers positions of concrete and steel support, efficiency of mechanical construction, and other factors. After each layer is completely excavated, supports and concrete pouring between piles are completed in time to ensure construction safety of foundation pit.

\section{(2) Shoring scheme}

It is planned that standard section supports use three anchor cables plus three internal supports. The first anchor cable is $3 \Phi 12.7$ steel strand, the second and the third anchor cables are 3Ф15.2 steel strand, and the fourth, fifth and sixth supports are $700 * 1,000 \mathrm{~mm}$ side reinforced concrete supports. Due to combined construction of the major structure of the station and Ventilation Pavilion 2, the south end foundation pit of the station is $40.25 \mathrm{~m}$ wide, and the internal supporting for the foundation pit is three side reinforced concrete supports, with a supporting section of $700 * 1,000 \mathrm{~mm}$. Enclosure purlin for side reinforced concrete supports uses reinforced concrete waist rail. In computation model, concrete is grade C30. In consideration of impact of slight crack produced under working condition, after concrete rigidity multiplies 0.8 , elasticity modulus is deemed to be $24 \mathrm{GPa}$, Poisson's ratio 0.2 and density $2,500 \mathrm{~kg} / \mathrm{m}^{3}$.

\section{FLAC 3D Simulation}

\subsection{Calculation Model and Parameters}


(1) Selection for Boundary Scope

The plan dimension of foundation pit in standard section is: $182.10 \mathrm{~m} \times 30.05 \mathrm{~m}$. The general shape of foundation pit is a long and narrow rectangular shape, whose $1 / 2$ shall be taken for model calculation according to its symmetry. The max excavation depth of foundation pit is $17.40 \mathrm{~m}$ and the foundation is excavated in four steps. In the basic analysis model, the distance we take between truncated boundary of long side of foundation pit to the pit side is five times of excavation depth, while the plan dimension of foundation pit in $1 / 2$ calculated model is: $91.05 \mathrm{~m} \times 30.05 \mathrm{~m}$, and the dimension of model master plan is $178.05 \mathrm{~m} \times 204.06 \mathrm{~m}$.

The effect that the model's below section boundary has on the model is less than the vertical truncated section does. Usually we take the distance between below section boundary to the pit bottom as 3 4 times of finally excavated depth, so we take $60 \mathrm{~m}$ for the model. Then the 3D dimension of $1 / 2$ calculated model is $178.05 \mathrm{~m} \times 204.06 \mathrm{~m} \times 60.00 \mathrm{~m}$. The support shall be simulated by beam unit while the enclosure structure shall be simulated by entity unit. See Diagram 3 for foundation pit and its soil mass model and see Sheet 1 for calculated parameters.

(2) Confirmation for boundary constraint conditions:

The outer boundary of calculated model and also two vertical sides $x=178.05 m$ and $y=92.03 m$ only constraints the normal displacement of boundary and no constraint for plan; the horizontal boundary on model bottom $\mathrm{z}=-60.00 \mathrm{~m}$ adopts fixed constraint; two symmetrical boundaries $x=0 \mathrm{~m}$ and $\mathrm{y}=0 \mathrm{~m}$ adopts constraint conditions of symmetrical boundary; horizontal ground surface $\mathrm{z}=0 \mathrm{~m}$ is free surface.

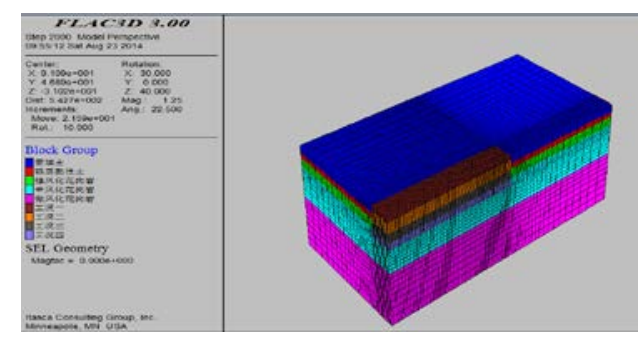

Fig 3. Deep excavation and $1 / 4$ model of soil

(3) Selection for model parameters

According to Mohr--Coulomb yield criterion, see all necessary parameters in Sheet 2 for model calculation.

Table 2. All Parameters for Model Calculation

\begin{tabular}{c|c|c|c|c|c}
\hline $\begin{array}{c}\text { Rock-Soil } \\
\text { Layer }\end{array}$ & Rock-Soil Name & $\begin{array}{c}\text { Bulk } \\
\text { Modulus K } \\
{[\mathrm{Mpa}]}\end{array}$ & $\begin{array}{c}\text { Shear } \\
\text { Modulus G } \\
{[\mathrm{Mpa}]}\end{array}$ & $\begin{array}{c}\text { Cohesion C } \\
{[\mathrm{Kpa}]}\end{array}$ & $\begin{array}{c}\text { Internal } \\
\text { Friction } \\
\text { Angle }\left[{ }^{\circ}\right]\end{array}$ \\
\hline (1)2 & Plain Fill & 5.56 & 1.85 & 8 & 20 \\
\hline
\end{tabular}




\begin{tabular}{c|c|c|c|c|c}
\hline (7)1 & Gravelly Cohesive Soil & 12.5 & 5.77 & 20 & 20 \\
\hline 82 & $\begin{array}{c}\text { Intensively Weathered } \\
\text { Granite }\end{array}$ & 34.8 & 18.1 & 40 & 30 \\
\hline 83 & $\begin{array}{c}\text { Intermediately Weathered } \\
\text { Granite }\end{array}$ & 3333.3 & 2000 & 3000 & 35 \\
\hdashline 84 & $\begin{array}{c}\text { Slightly Weathered } \\
\text { Granite }\end{array}$ & 13095.2 & 9016.4 & 8000 & 43 \\
\hline
\end{tabular}

\subsection{Simulation Solution}

To truly and accurately simulate the excavation process of foundation pit, Null of FLAC ${ }^{3 \mathrm{D}}$ software is used for simulating excavation. In FLAC ${ }^{3 \mathrm{D}}$, NULL unit presents the soil excavated from the model, while the stress in Null shall be automatically set as Zero. The specific excavation procedures are as follows: Initial step: Building model---balance calculation before excavation--- Forming initial stress field of soil before excavation. Remove the displacement field corresponding to initial stress field and only keep the initial stress.

Work Status I: Excavating till -1.6m to surface of foundation pit, installing the $1^{\text {st }}$ support at $-1.6 \mathrm{~m}$, calculating to make it balanced.

Work Status II: Excavating till $-8.0 \mathrm{~m}$ to surface of foundation pit, installing the $1^{\text {st }}$ anchor cable at $-8.0 \mathrm{~m}$, calculating to make it balanced.

Work Status III: Excavating till $-13.0 \mathrm{~m}$ to surface of foundation pit, installing the $2^{\text {nd }}$ anchor cable at $-13.0 \mathrm{~m}$, calculating to make it balanced.

Work Status IV: Excavating till $-17.4 \mathrm{~m}$ to surface of foundation pit, calculating to make it balanced.

Table 3 .Main Calculation Stage for Foundation Pit Construction

\begin{tabular}{|c|c|c|}
\hline Calculation Stage & $\begin{array}{l}\text { Cycle Number on } \\
\text { Each Stage }\end{array}$ & Construction Work Status \\
\hline Stage0 & 2000 & $\begin{array}{l}\text { Calculating the initial ground stress, } \\
\text { displacement is Zero }\end{array}$ \\
\hline Stage1 & 3000 & $\begin{array}{l}\text { Excavating the } 1^{\text {st }} \text { layer of soil till } \\
\text { bottom surface of the } 1^{\text {st }} \text { layer of } \\
\text { support, with concrete support for the } \\
\text { construction at the } 1^{\text {st }} \text { time }(-1.6 \mathrm{~m})\end{array}$ \\
\hline Stage2 & 3000 & $\begin{array}{l}\text { Excavating the } 2^{\text {nd }} \text { layer of soil till } \\
\text { bottom surface of the } 2^{\text {nd }} \text { layer of } \\
\text { support, with concrete support for the } \\
\text { construction at the } 1^{\text {st }} \text { time }(-8.0 \mathrm{~m})\end{array}$ \\
\hline Stage3 & 3000 & $\begin{array}{l}\text { Excavating the } 3^{\text {rd }} \text { layer of soil till } \\
\text { bottom surface of the } 3^{\text {rd }} \text { layer of } \\
\text { support, with concrete support for the } \\
\text { construction at the } 3^{\text {rd }} \text { time }(-13.0 \mathrm{~m})\end{array}$ \\
\hline Stage4 & 3000 & Excavating till pit bottom \\
\hline
\end{tabular}


$(-17.4 \mathrm{~m})$

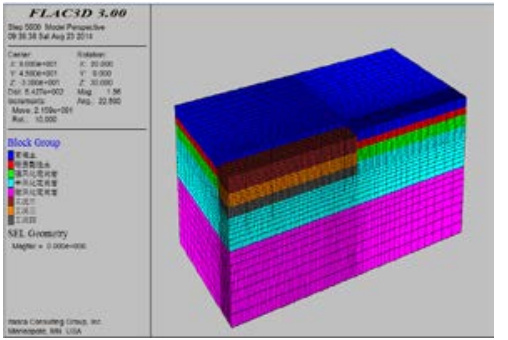

(a) Work 1

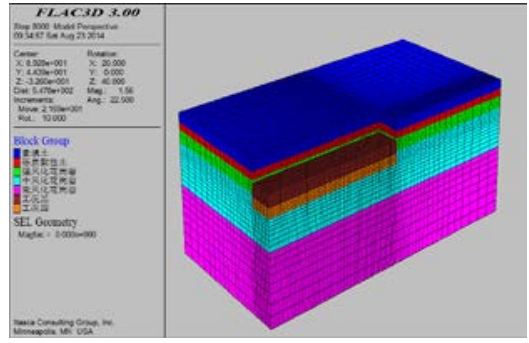

(b) Work 2

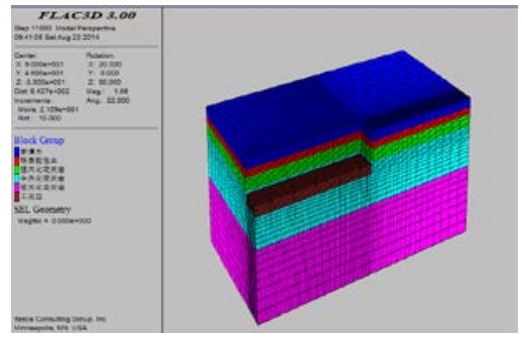

(c) Work 3

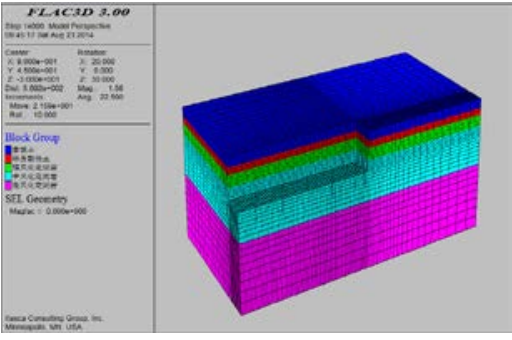

(d) Work 4

Fig 4. All Construction Work Status Diagram

\section{Analysis on Calculated Result}

\subsection{Analysis on Foundation Pit Displacement}

When excavating the pit bottom, because of demolishment for upper load, the load-carrying capacity of pit bottom soil mass is unbalanced, and the pit bottom has upheaval. Meanwhile, the upheaval of soil mass of pit bottom shall surely cause the movement of surrounding soil. The enclosure structure has horizontal displacement tendency in the direction of foundation pit because it's extruded by stress of side soil, which shall affect the surrounding soil mass, and lead to the displacement in vertical direction. The soil mass in middle of foundation pit has tendency of upheaval while the soil mass surrounding foundation pit has tendency of sinking. Chart 5 presents the vertical displacement cloud chart of foundation pit during the whole excavation process, from Chart we can see the vertical displacement of foundation pit in the whole excavation process is small. From Chart 5 (a) we can see that, when excavation goes till $1.6 \mathrm{~m}$, the maximum upheaval height of pit bottom is $19 \mathrm{~mm}$; in the following excavation process, because the shoring of foundation beam and physical and mechanical property change of soil mass, the maximum upheaval height is decreased; from Fig.5(b) we 
can see that, when excavation goes till $8 \mathrm{~m}$, the maximum displacement of foundation pit upheaval is $10.7 \mathrm{~m}$. From 5(c) and (d) we can get that the maximum displacement of vertical displacement of foundation pit at $13 \mathrm{~m}$ and $17.4 \mathrm{~m}$ respectively are $0.9 \mathrm{~mm}$ and $1.6 \mathrm{~mm}$. Under Work Status I, the settlement change of the earth's surface is small, and the maximum value of earth's settlement surrounding foundation pit is 1.3mm. As indicated in Fig.5 (b), under Work Status 3 and 4, the earth's surface settlement value surrounding foundation pit is getting higher and higher, and the maximum earth's surface settlement value surrounding the foundation pit are respectively $2 \mathrm{~mm}$ and $2.5 \mathrm{~mm}$, as indicated in Fig.5 (c) \& (d) The maximum value of earth's surface settlement occurs at the place with certain distance to foundation pit, not on the edge of foundation pit.

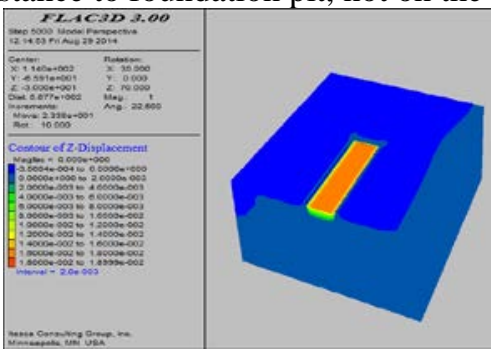

(a) Work 1

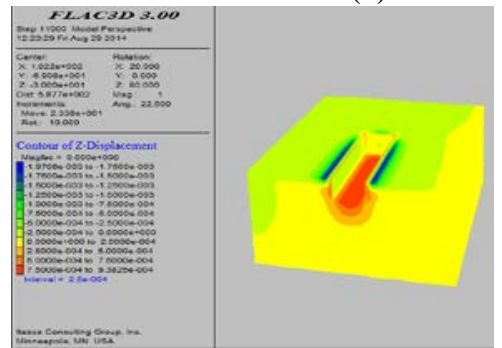

(c) Work 3

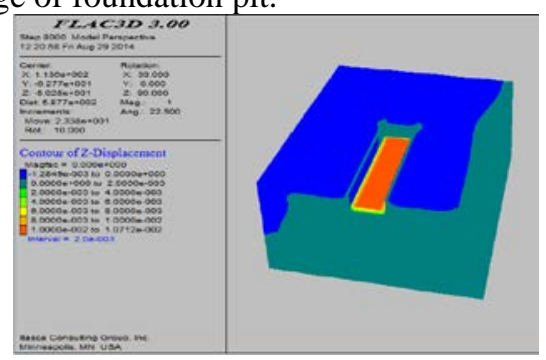

(b) Work 2

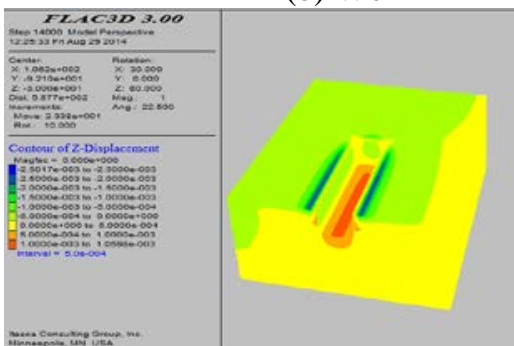

(d) Work 4

Fig 5. Vertical Displacement of Foundation Pit under All Construction Work Status

Fig.6 presents the horizontal displacement clout chart during the whole excavation process for foundation pit, from the chart we can see that during the whole process, the horizontal displacement of foundation pit is small. From Fig.6 (a) we can see that when excavation goes till $1.6 \mathrm{~m}$, the maximum displacement of enclosure wall is $3 \mathrm{~mm}$; in the following excavation process, because the support of foundation beam, the maximum value of foundation pit displacement is continuously increased; from Fig.6 (b) we can see that, when excavation goes till $8 \mathrm{~m}$, the maximum displacement of enclosure wall is $10.2 \mathrm{~m}$. The maximum displacement of horizontal displacement of foundation pit at $13 \mathrm{~m}$ and $17.4 \mathrm{~m}$ respectively are $13.8 \mathrm{~mm}$ and $15.9 \mathrm{~mm}$, as indicated in Fig.6 (c) \& (d). From horizontal displacement of foundation pit under all construction work status in Chart 6 , we can get that, as the excavation of foundation pit, the horizontal 
displacement of pile body shall be higher and higher gradually, meanwhile, the position of pile with the maximum horizontal displacement is not fixed on certain specific position.

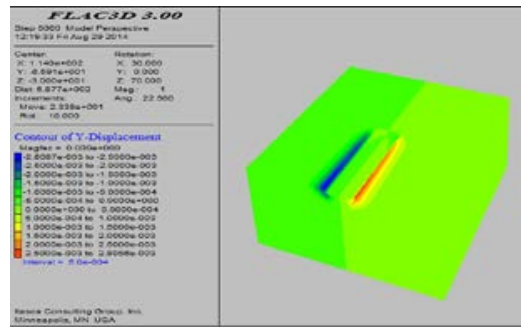

(a) Work 1

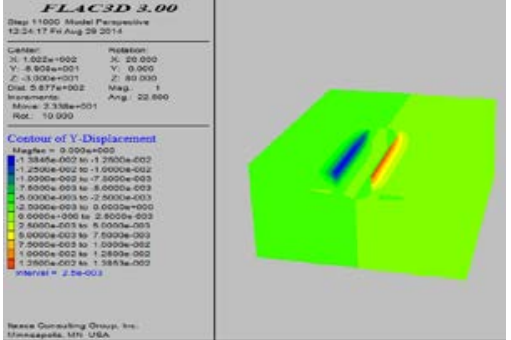

(c) Work 3

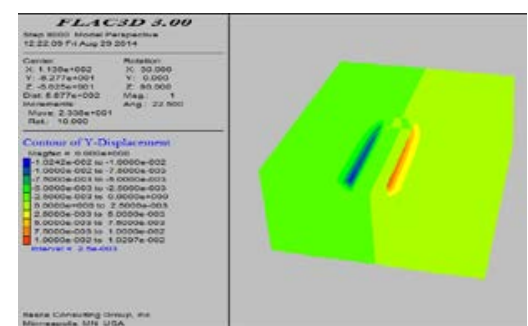

(b) Work 2

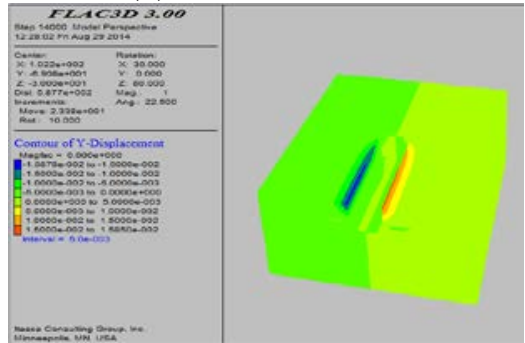

(d) Work 4

Fig 6. Horizontal Displacement of Foundation Pit under All Construction Work

\subsection{Analysis on Axial Force}

Status

From Fig.7 we can get that, under Work Status II, the axial force of concrete support is $8.86 \mathrm{KN}$; as the excavation of foundation pit, the axial force is increased gradually; under Work Status III, the axial force reaches $7.46 \mathrm{KN}$; under Work Status IV, the axial force reaches $8.86 \mathrm{KN}$; In the whole process the axial force of concrete support is small and basically gets stable. Therefore, the main part has no need to add anchor cable to decrease the axial force of concrete support, which satisfies the project reality.

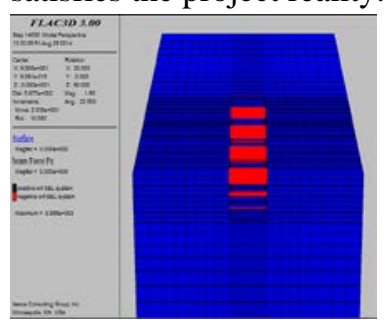

(a) Work 2

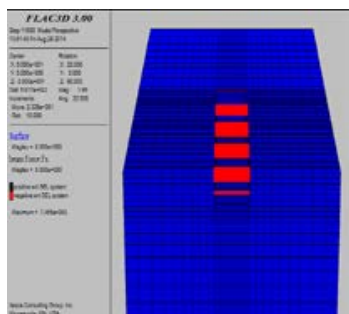

(b) Work 3

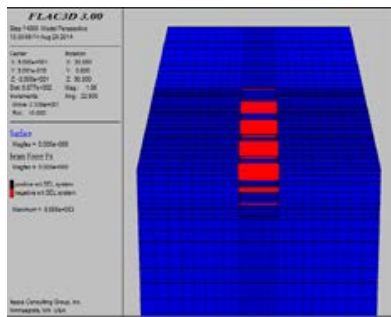

(c) Work4

Fig 7. Axial Force Distribution Chart under All Construction Work Status

\subsection{Analysis on Earth's Surface Settlement}


From Fig.8 we can get that, under Work Status I, the earth's surface settlement is small, from the near end of foundation pit to its faraway end the settlement gets smaller and smaller. Under Work Status II \& III, the earth's surface settlement is increased obviously, and the maximum value of settlement occurs at the place with $5 \sim 10 \mathrm{~m}$ to foundation pit rather than edge of foundation pit. Under Work Status IV, the settlement of earth's surface becomes stable gradually and the maximum value is about $11.7 \mathrm{~m}$ which is far smaller than alarm value $30 \mathrm{~mm}$. Simulated result basically reflects the settlement situation of earth's surface surrounding the foundation pit during construction process, which shall provide the data for the same project simulation with $\mathrm{FLAC}^{3 \mathrm{D}}$ in the future and estimation analysis.

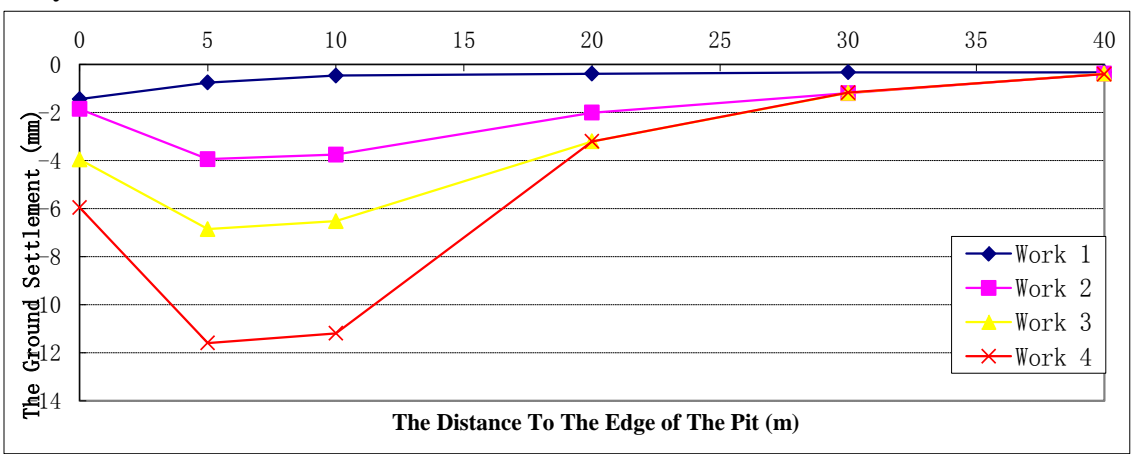

Fig.8 Curve Chart of Earth’s Surface Settlement under All Work Status

\subsection{Piles Displacement}

See Fig.9 for the simulated result of pile displacement. We can see that, the construction process for deep foundation pit is a complicated process affected by many factors. In this case, the real result has certain difference from the simulated result. Main factors that affect the safety on construction phase of foundation pit project are: underground water, weather, construction machinery, tau-effect, etc. These types of factors are also presented in the data for construction site monitoring. Numerical simulating calculation, though the constitutive model of soil mass is suitable for characteristics of rock-soil project material, does not consider the tau-effect of foundation pit deformation. In many cases, earthwork excavation is suspended in the middle because of construction reasons, which shall lead to the long-term exposure of excavated surface. From Fig.9 we can get that, the displacement of pile cap is the maximum but becomes smaller and smaller as downwards. As the erection of concrete support and excavation for foundation pit, the displacement of pile cap becomes larger gradually but the change is not big. As the excavation for the $3^{\text {rd }}$ and $4^{\text {th }}$ time, the displacement of pile becomes large gradually, but with the constraint from the $1^{\text {st }}$ and $2^{\text {nd }}$ layer of concrete support, the pile displacement is not increased infinitely. As the completion of foundation pit excavation, the deformation becomes stable; during this period, the vertical displacement of pile cap has tendency of becoming larger but the change is not big, as indicated in Fig.9 (c) \& (d). From the above analysis we can get that, though the real result has certain difference on numerical value from simulated result, the 
general change tendency is consistent, which explains that the model building and parameter selection and calculated method are reasonable and correct. Simulated result can obviously reflects the general rules of foundation pit deformation.

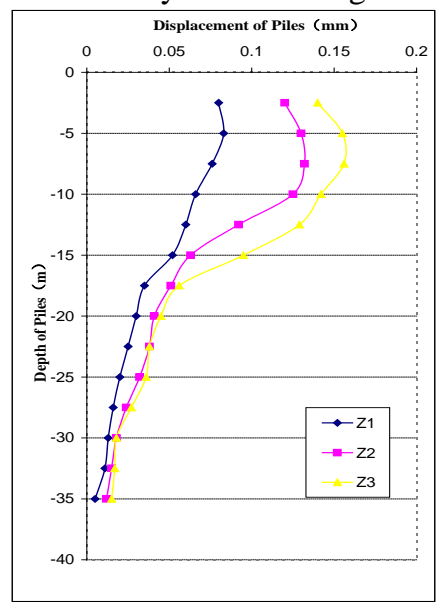

(a) Work 1

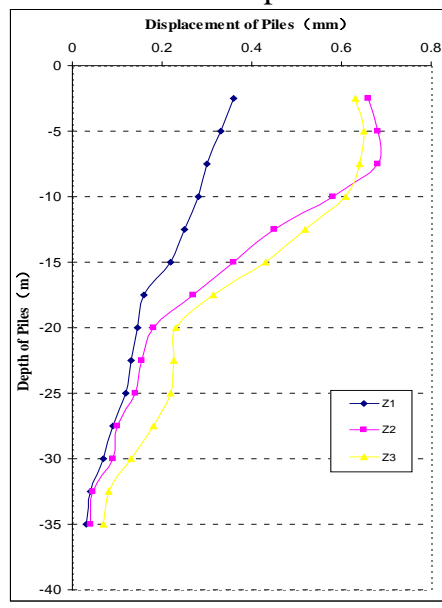

(b) Work 2

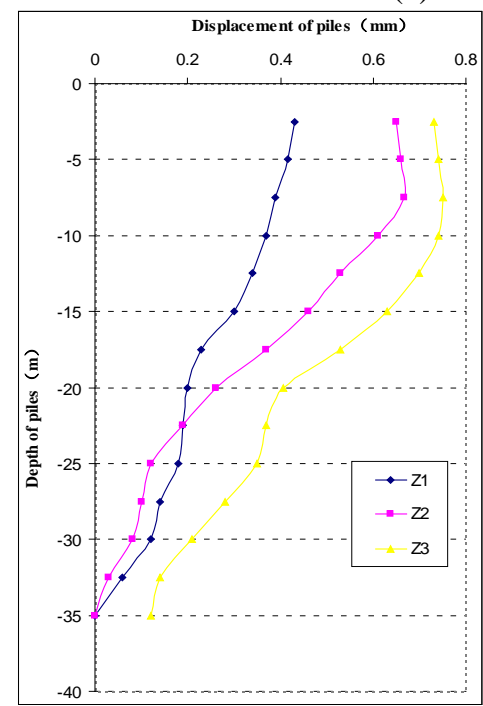

(c) Work 3

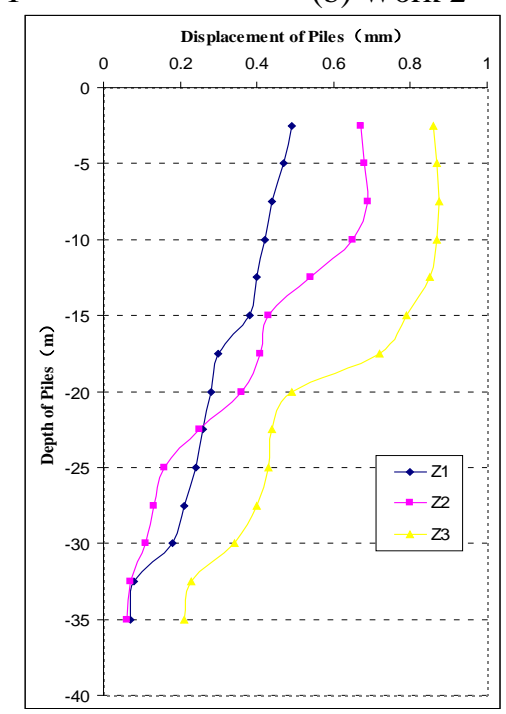

(d) Work 4

Fig. 9 Piles Displacement

\section{Conclusion}


With FLAC ${ }^{3 \mathrm{D}}$, we do numerical simulation for Shenzhen Metro Line 7 (at Antuoshan Station) on deep foundation pit excavation and shoring process on later phase, and we get the following conclusion:

(1) Studying destroy mode of deep foundation pit is of great importance in its shoring design. Using destroy mode of foundation pit can promote the support selection efficiency, make estimation for dangerous position of foundation pit support structure and provide reference basis for foundation pit design, it also has certain type of predictability on safety.

(2) In this example, FLAC ${ }^{3 D}$ numerical simulation reappears the whole process of deep foundation excavation, which proves that, caused by foundation pit excavation, the stress and strain change rules of soil and shoring structure in 3D space and concludes that, at the position with 1/2 excavation depth of foundation pit, the deformation of soil and support structure is the maximum, which also proves that the destroy type and mode of foundation pit as well as calculation theory is similar.

(3) In this example, the enclosure structure deformation presents strong space effect: the horizontal displacement of enclosure structure in the middle of foundation pit is the maximum; the closer to angle point of foundation pit, the smaller the horizontal displacement of enclosure structure becomes. The axial force distribution of concrete support also presents the obvious space effect: the force of support in the middle of foundation pit is the maximum, the closer to angle point, the smaller the support force will be. The earth's surface settlement presents that: the settlement from foundation pit edge to the position with $5 \sim 8 \mathrm{~m}$ away from foundation pit becomes larger gradually; or else, the farther to foundation pit, the smaller the settlement will be, till stable.

\section{References}

[1]. Itasca Software Comp. Theory and back ground constitutive model: theory and implementation [P]. User Manual of $\mathrm{FLAC}^{3 \mathrm{D}}$ 2.0, 2002.

[2]. Itasca Software Comp. Interfaces [P]. User Manual of FLAC ${ }^{3 \mathrm{D}}$ 2.0, 2002

[3]. Itasca Software Comp. Structure elements [P]. User Manual of FLAC ${ }^{3 \mathrm{D}} 2.0$, 2002.

[4]. Itasca Consulting Group, Inc. Fast lagrangian Analysis of continua [M]. Itasca Consulting Group, Inc. 1994.

[5]. Rowe P W. Anchored sheet-pile walls [J]. Institution of Civil Engineers, London, Proceedings, 1952(1): 27-70

[6]. Borwn PT, Booker J R. Finite element analysis of excavation [J]. Computer and Geotechnique.1985, 1(3): 102-113.

[7]. Clough G. W., Duncan J. M.. Finite element analysis of retaining wall behavior [J]. ASCE, 1971, Vol.97SM, 12:165-167.

[8]. Sunil. S. Kishnani, Seepage and soil-structure interface effects in braced excavations [J]. Journal of Geotechnical Engineering, 1993, 119(5), 912-929. 
[9]. Charlis. W. Ng, Martin. L. Lings. Effects of modeling soil nonlinearity and wall installation on back-analysis of deep excavation in stiff clay J]. Journal of Geotechnical Engineering, 1995, 12(10): 687-695.

[10]. Peck, R. B. (1969). Deep excavations and tunneling in soft ground. Proc, 7th Int. Conf. Soil Mech. Found. Engorge, 225-281.

[11]. Clough, G. W.,Smith, E. M.,and Sweeney, B. R( 1989). Movement control of excavation support systems by iterative design [J]. Proc. ASCE Found. Engineering: Current Principles and Pract, Vol.11 ASCE,New York, 869-884.

[12]. Moor Mana C. Analysis of wall and ground movements due to deep excavations in soft soil based on a new worldwide database [J]. Soils Found, 2004,44(1): 87 - 98.

[13]. Terzagh K, and Peck R.B.. Soil Mechanics in Engineering Practice. Second edition[J]. John Wiley\& Sons, New York, 1967.

[14]. Ou, C. Y,Hsien, P. G,and Chiou, D. C. Characteristics of ground surface settlement during excavation[J]. Can. Geotech. J., Ottawa, 1993(30); 758-767.

[15]. Card D R. Ground movements caused by different embedded retaining wall construction techniques[J]. TRL Rep. No. 172, Transport Research Laboratory, Crowthome,U.K. 1995.

[16]. Ou, C. Y” Hsien, P. G.,and Chiou, D. C. (1993). Characteristics of ground surface settlement during excavation [J]. Can. Geotech. J.,Ottawa, 30 , 758-767.

[17]. Ou C.Y., Chiou D.C., and Wu T.S. Three-dimensional finite element analysis of deep excavations [J]. Journal of Geotechnical Engineering, ASCE, 1996, 122(5): 337-345.

[18]. Liu Ji-Guo, Zeng Ya-wu, Application of FLAC ${ }^{3 D}$ to simulation of foundation excavation and support [J]. Chinese Rock and Soil Mechanics, 2006, Vol.27 (3).In Chinese.

[19]. Roboski J.R. Three-diniensional performance and analyses of deep excavations [M]. PhD thesis, Northwestern University, Evanston, Illinois, 2004.

[20]. Yoo C. Behavior of braced and anchored walls in soils overlying rock [J],Journal of Geotechnical and Geoenvironmental Engineering, 2001,127(3):225- 233.

[21]. OU C Y, HSIEH P G,CHIOU D C. Characteristics of ground surface settlement during excavation[J]. Canadian Geotechnical Journal, 1993,35: $758-767$.

[22]. Karlsrud, K. Performance monitoring in deep supported excavations in soft clay. Proc [J], 4th Int. Geo. Seminar, Field Instrumentation and In-Situ Measurement, Nanyang Technological Institute, Singapore, 1986: 187-202. 